\title{
Sex differences in the clinical presentation and management of airflow obstruction
}

\author{
R.E. Dales*, A. Mehdizadeh*, S.D. Aaron*, K.L. Vandemheen ${ }^{\#}$ and J. Clinch $^{\#}$
}

\begin{abstract}
The aim of the present study was to explore differences in the clinical expression, clinical diagnoses and management of airway diseases in a primary-care setting.

Patients aged $\geqslant 35$ yrs who had ever smoked were enrolled when they presented for any reason to one of eight rural primary-care practices. Respiratory symptom questionnaires and spirometry were administered. In total, 1,034 patients had acceptable and reproducible spirometry, of whom $550(53 \%)$ were males and $484(47 \%)$ were females.
\end{abstract}

Males smoked more than females (41.2 versus $\mathbf{2 9 . 2}$ pack-yrs) respectively, and were more likely to have a pre-bronchodilator forced expiratory volume in one second/forced vital capacity $<0.70$ at 22.4 versus $11.8 \%$, respectively. However, more females than males reported breathlessness ( 51.0 versus $42.8 \%$, respectively), a prior diagnosis compatible with airflow obstruction and taking respiratory medications (23.4 versus $14.9 \%$, respectively).

In conclusion, the current results suggest that females are more likely than males to report breathlessness and be prescribed respiratory medications independent of differences in the severity of airflow obstruction.

KEYWORDS: Airflow obstruction, clinical practice, sex, spirometry, treatment

$\mathbf{T}$ he most common causes of airflow obstruction in primary-care practices are chronic obstructive lung disease (COPD), characterised by progressive, partially reversible airway obstruction, and asthma, characterised by variable airflow limitation [1,2]. Previous studies have shown that the clinical diagnosis of chronic bronchitis is made more commonly in females than males, and emphysema is more commonly diagnosed in males than females [3]. Hypothetical case presentations to primary-care physicians reveal that, for the same clinical history, males were more likely to be diagnosed with COPD and females with asthma [4]. Whether or not females are more susceptible to cigarette smoke than males is controversial. A recent study in a pulmonary clinic matched females to males on forced expiratory volume in one second (FEV1) per cent predicted [5]. Compared with males, females were younger, smoked less, were more breathless and reported poorer quality of life scores. The present study explores differences in clinical expression of airway disease, diagnoses and management in a primary-care setting. The study group was not selected based on the presence or absence of respiratory symptoms or known lung disease.

For editorial comments see page 259.

\section{METHODS}

\section{Geographical location}

Primary-care practices were recruited from rural Eastern Ontario, Canada. They had to be within a 2-h driving distance of the Ottawa Hospital (Ottawa, ON, Canada), which allowed the hospital-based research assistants to drive to the practices each day to perform spirometry. Several rural communities were selected to assess variability between practices. The practices were sent letters of invitation and then contacted via were included in the study.

\section{Subjects}

Eligible subjects were all patients presenting to their primary-care practitioners for any reason, who were aged $\geqslant 35 \mathrm{yrs}$, and who had smoked $\geqslant 20$ packets of cigarettes in their lifetime. The patients were given a brief questionnaire by the clinic receptionist to determine their age and smoking history, and were asked whether they would agree to participate. Patients who were eligible and agreed to participate were approached by the research assistant and signed informed consent forms. Patients who could not perform spirometry were excluded. The study was approved by the Ottawa Hospital Human Ethics Committee. telephone. The first eight practices that agreed
AFFILIATIONS

*Dept of Medicine, University of

Ottawa, and,

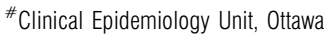
Health Research Institute, Ottawa,

ON, Canada

CORRESPONDENCE

R.E. Dales

Division of Respirology

The Ottawa Hospital (General

Campus)

501 Smyth Road

Box 211

Ottawa

Ontario K1H 8L6

Canada

Fax: 16137396266

E-mail: rdales@ohri.ca

Received:

November 232005

Accepted after revision:

April 262006

SUPPORT STATEMENT

The present study was supported by an unrestricted grant from

GlaxoSmithKline. The study was

conceived by the authors alone, and GlaxoSmithKline had no role in the design, implementation, analysis, or interpretation of the study result. The authors of the present study have no competing interest to declare. 


\section{Baseline data collection}

Interviewer-administered questionnaires included questions about smoking, respiratory symptoms and diagnosed respiratory illnesses, and were taken from the American Thoracic Society (ATS) Questionnaire [6], which has been standardised and tested for reliability.

Spirometry was performed in the primary-care practice building by trained research assistants using a Microlab $350{ }_{\circledR}$ (Micro Medical Ltd, Kent, UK). Testing was carried out with the subjects seated. A maximum forced exhalation was carried out for a minimum of $6 \mathrm{~s}$. A minimum of three and a maximum of eight forced vital capacity (FVC) manoeuvres were performed to obtain at least three acceptable loops, two of which were reproducible within $200 \mathrm{~mL}$. The reference values for FEV1 and FVC were those of KNUDSON et al. [7]. Postbronchodilator FEV1 was measured $20 \mathrm{~min}$ after $200 \mu \mathrm{g}$ of salbutamol in those with an FEV1/FVC $<70 \%$ pred or an FEV1 $<80 \%$ pred. All spirometry tests were reviewed by an independent senior cardiopulmonary technologist and two respirologists to ensure acceptability.

\section{Statistical analysis}

Two different criteria were used for determining the prevalence of airflow obstruction. The first was an FEV1/FVC $<70 \%$ pred, the clinical threshold criteria popularised by the Global Initiative for Chronic Obstructive Lung Disease guidelines for the diagnosis of airflow obstruction [8]. The second definition was a pre-bronchodilator FEV1/FVC1 less than the lower limits of normal (LLN), based on reference equations determined by the third National Health and Nutrition Examination Survey spirometric data [9]. Results were stratified by sex and differences were tested either with an independent unpaired t-test or Chi-squared statistics.

\section{RESULTS}

The study included eight communities with populations between 1,206 and 4,406, of which 1,046 subjects were enrolled. A total of 1,034 subjects had acceptable and reproducible spirometry, of whom $550(53 \%)$ were males and $484(47 \%)$ were females. There was no significant difference in prevalence of airflow obstruction between the eight study sites (Chi-squared, $p=0.17$ ). The mean \pm SD age of the study patients was $59 \pm 12.7$ yrs, with patients having a smoking history mean \pm SD of $35.5 \pm 28.5$ pack-yrs.

To determine the degree to which the study group was representative of all eligible subjects, the entire clinical population that visited the eight primary-care practices was surveyed for several days. Of the 1,800 subjects who were $100 \%$ sampled, 561 were $\geqslant 35$ yrs of age and had ever smoked. Compared with all of those eligible (aged $\geqslant 35 \mathrm{yrs}$ and had ever smoked), the group studied using spirometry differed as follows: 1) aged 2 yrs younger; 2) 1\% more males; and 3) $1 \mathrm{yr}$ extra smoking.

In the study group of 1,034, males were on average 5.5 yrs older and had smoked for 12 pack-yrs more than females $(p<0.0001 ;$ table 1). Females reported dyspnoea $(p=0.008)$ and wheeze $(p=0.031)$ more frequently. Based on responses to the ATS Questionnaire [6], females were twice as likely to have been diagnosed with asthma, 20 versus $10 \%(\mathrm{p}<0.0001)$, respectively, and two-thirds more likely to have been diagnosed with chronic bronchitis, 19 versus $11 \%(p=0.001)$, respectively. The prevalence of airflow obstruction was higher in males than females. This was statistically significant when defined by FEV1/FVC $<70 \%$ pred, but not significant when defined by the LLN criteria. In total, 123 (22\%) males and 57 $(12 \%)$ females had an FEV1/FVC $<70 \%$ pre-bronchodilator $(\mathrm{p}<0.0001)$. FEV1/FVC less than LLN was present in $76(14 \%)$ males and $54(11 \%)$ females $(p=0.20)$. Females were also almost twice as likely to report using respiratory medications, 23 versus $15 \%(p=0.0005)$, respectively.

When the analysis was restricted to only those with obstruction defined by the LLN criteria, females had smoked less than males, 39 versus 53 pack-yrs $(\mathrm{p}=0.0008)$, respectively. They were also much less likely to report sputum, 17 versus $41 \%$, respectively, (table 2). There were no significant sex differences in reported respiratory diseases and medications.

Respiratory medication use was stratified by severity of obstruction from none to severe (table 3). Females were twice as likely as males to be prescribed medications unless airway obstruction was severe. When severe, $70 \%$ of both males and females reported taking at least one respiratory medication.

\begin{tabular}{|c|c|c|c|}
\hline Characteristics & Males & Females & $\mathrm{p}$-value \\
\hline Subjects & $550(53)$ & $484(47)$ & \\
\hline Age yrs & $61.7 \pm 12.4$ & $56.2 \pm 12.5$ & $<0.0001$ \\
\hline $\begin{array}{l}\text { Post-secondary } \\
\text { education }\end{array}$ & $139(25.7)$ & $111(23.3)$ & 0.3792 \\
\hline $\begin{array}{l}\text { Smoking history } \\
\text { pack-yrs }\end{array}$ & $41.2 \pm 32.3$ & $29.2 \pm 21.8$ & $<0.0001$ \\
\hline \multicolumn{4}{|l|}{ Symptoms } \\
\hline Shortness of breath & 235 (42.8) & $247(51.0)$ & 0.0082 \\
\hline Cough & $108(19.7)$ & $119(24.6)$ & 0.0570 \\
\hline Phlegm & $126(22.9)$ & $95(19.7)$ & 0.2051 \\
\hline Wheeze & 209 (38.0) & $216(44.6)$ & 0.0307 \\
\hline \multicolumn{4}{|l|}{ Diagnoses } \\
\hline Asthma & $56(10.2)$ & $96(20.0)$ & $<0.0001$ \\
\hline COPD & $15(2.7)$ & $20(4.2)$ & 0.2097 \\
\hline Emphysema & $20(3.7)$ & $12(2.5)$ & 0.2846 \\
\hline Chronic bronchitis & $62(11.4)$ & $88(18.7)$ & 0.0010 \\
\hline FEV $1 /$ FVC $<0.70$ & $123(22.4)$ & $11.8(57)$ & $<0.0001$ \\
\hline Severe & $29(5.3)$ & $11(2.3)$ & \\
\hline Moderate & $69(12.6)$ & $36(7.4)$ & \\
\hline Mild & $25(4.6)$ & $10(2.1)$ & \\
\hline $\mathrm{FEV}_{1 / \text { FVC }}<$ LLN & $76(13.8)$ & $54(11.2)$ & 0.2021 \\
\hline Severe & $23(4.2)$ & $10(2.1)$ & \\
\hline Moderate & $43(7.8)$ & $33(6.8)$ & \\
\hline Mild & $10(1.8)$ & $11(2.3)$ & \\
\hline Respiratory medication & $82(14.9)$ & $113(23.4)$ & 0.0005 \\
\hline
\end{tabular}

Data are presented as $n(\%)$ or mean $\pm S D$, unless otherwise stated. COPD: chronic obstructive pulmonary disease; FEV1: forced expiratory volume in one second; FVC: forced vital capacity; LLN: lower limits of normal. 


\begin{tabular}{|c|c|c|c|c|}
\hline \multirow{2}{*}{$\begin{array}{l}\text { TABLE } 2 \\
\text { Characteristi }\end{array}$} & \multicolumn{4}{|c|}{$\begin{array}{l}\text { Characteristics of } 130 \text { subjects with a forced } \\
\text { expiratory volume in one second/forced vital } \\
\text { capacity less than the lower limit of normal based } \\
\text { on the third National Health and Nutrition } \\
\text { Examination Survey spirometry data }\end{array}$} \\
\hline & & Males & Females & $p$-value \\
\hline Subjects & & 76 (58) & $54(42)$ & \\
\hline Age yrs & & $62.9 \pm 12.8$ & $60.3 \pm 13.9$ & 0.2807 \\
\hline $\begin{array}{l}\text { Post-seconda } \\
\text { education }\end{array}$ & & $17(23.0)$ & $11(20.4)$ & 0.7250 \\
\hline $\begin{array}{c}\text { Smoking hist } \\
\text { pack-yrs }\end{array}$ & & $52.9 \pm 28.2$ & $38.6 \pm 19.0$ & 0.0008 \\
\hline \multicolumn{5}{|l|}{ Symptoms } \\
\hline Shortness o & breath & $50(65.8)$ & 33 (61.1) & 0.5843 \\
\hline Cough & & $32(42.1)$ & $14(25.9)$ & 0.0573 \\
\hline Phlegm & & $31(40.8)$ & $9(16.7)$ & 0.0033 \\
\hline Wheeze & & $46(64.5)$ & $32(59.3)$ & 0.5455 \\
\hline \multicolumn{5}{|l|}{ Disease } \\
\hline Asthma & & 21 (27.6) & $21(40.4)$ & 0.1312 \\
\hline COPD & & $9(11.8)$ & $6(11.5)$ & 0.9582 \\
\hline Emphysema & & $13(17.3)$ & $4(7.7)$ & 0.1166 \\
\hline Chronic bro & chitis & $14(18.9)$ & $13(25.5)$ & 0.3803 \\
\hline Medication & & 29 (38.2) & $28(51.9)$ & 0.1210 \\
\hline
\end{tabular}

To determine if airflow obstruction was more likely to be reversible in females than males, bronchodilator response was stratified by sex and severity of obstruction (table 4). No significant differences were found between the sexes.

\section{DISCUSSION}

Females were more likely than males to report respiratory symptoms, which is consistent with the recent findings of DE TORRES et al. [5]. In addition, the current authors found that females were more likely to have received a diagnosis of a chronic airway disease, and were more likely to be taking respiratory medications. One possible explanation is a sex difference in the severity or expression of the disease. More females than males reported breathlessness, which was not explained by age, smoking history or FEV1. This relative increase in symptoms may explain the increased probability of being both diagnosed with lung disease and treated.

There also appears to be a sex-bias in the diagnosis of chronic bronchitis, which may influence population health statistics for respiratory disease. The defining symptom of bronchitis is mucus hypersecretion from the chest and does not require airflow obstruction to be present [10]. Although males generally reported more sputum production, consistent with this diagnosis, females in the present study were more likely to be labelled as having chronic bronchitis. American national population database studies have also reported a greater prevalence of chronic bronchitis in females compared with males [3]. The current results suggest that this observed difference may not reflect differences in mucus hypersecretion, but rather a physician diagnostic bias.

\section{TABLE 3 Prevalence of taking at least one respiratory medication by sex and severity in obstructed patients}

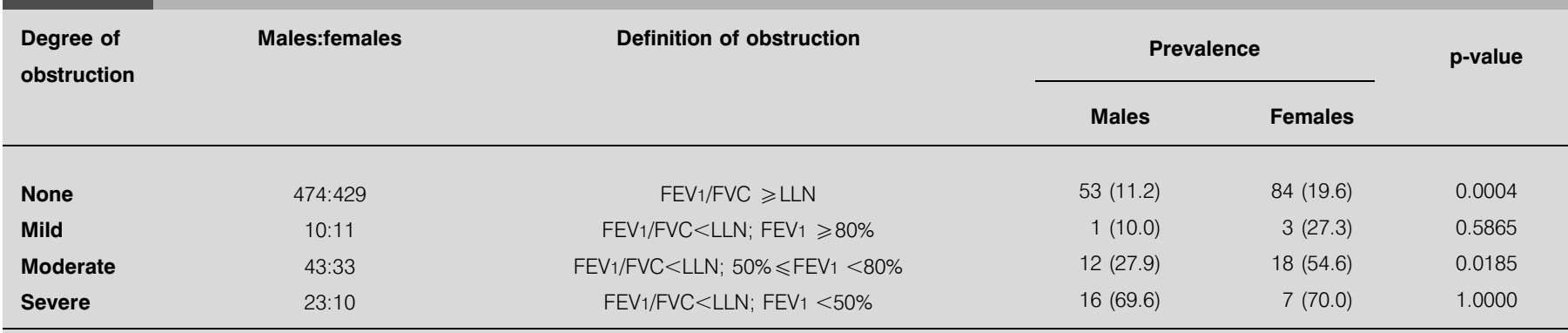

Data are presented as $\mathrm{n}$ or $\mathrm{n}(\%)$, unless otherwise stated. FEV1: forced expiratory volume in one second; FVC: forced vital capacity; LLN: lower limit of normal.

TABLE 4 Bronchodilator response by sex and severity of obstruction

\begin{tabular}{|c|c|c|c|c|c|}
\hline \multirow{2}{*}{$\begin{array}{l}\text { Degree of } \\
\text { obstruction }\end{array}$} & \multirow[t]{2}{*}{ Males:females } & \multirow[t]{2}{*}{ Definition of obstruction } & \multicolumn{2}{|c|}{ Mean bronchodilator response } & \multirow{2}{*}{ p-value } \\
\hline & & & Males & Females & \\
\hline Mild & $5: 7$ & $\mathrm{FEV}_{1} / \mathrm{FVC}<\mathrm{LLN} ; \mathrm{FEV} 1 \geqslant 80 \%$ & $5.1 \pm 5.5$ & $1.6 \pm 2.7$ & 0.1689 \\
\hline Moderate & 40:33 & $\mathrm{FEV}_{1 / \mathrm{FVC}}<\mathrm{LLN} ; 50 \% \leqslant \mathrm{FEV} 1<80 \%$ & $7.0 \pm 10.3$ & $7.7 \pm 12.1$ & 0.7815 \\
\hline Severe & $20: 10$ & $\mathrm{FEV}_{1} / \mathrm{FVC}<\mathrm{LLN} ; \mathrm{FEV} 1<50 \%$ & $12.6 \pm 12.0$ & $8.6 \pm 6.6$ & 0.3457 \\
\hline
\end{tabular}

Data are presented as $\mathrm{n}$ or mean $\pm \mathrm{SD}$, unless otherwise stated. FEV1: forced expiratory volume in one second; FVC: forced vital capacity; LLN: lower limit of normal. 
It is not possible to determine if the prevalence of asthma was truly higher in the female study population or whether there was a reporting bias. Self-reported asthma and bronchial hyperresponsiveness are known to be more common in adult females than adult males [11, 12]. CHAPMAN et al. [13] reported that clinicians presented with hypothetical cases were more likely to diagnose asthma in females than males despite similar age, smoking histories and symptoms. The present results also suggest a sex-bias in diagnosing asthma. Females were twice as likely as males to be diagnosed with asthma although bronchodilator responsiveness did not differ between the two groups. Females have been reported to use primary-care services with greater frequency, but to receive fewer specialist referrals than males and to be less likely than males to be referred for invasive cardiac procedures [4, 14, 15]. These findings raise the expectation that females may also be relatively under-treated for respiratory disease. The current authors found the opposite to be true. Females were more likely to be prescribed respiratory medications until severe obstruction was present (table 3). Males may be relatively under-treated at milder stages of airflow obstruction.

The two different criteria used to define airflow obstruction affected males and females differently in the present study. The FEV1/FVC ratio decreases with age among healthy adults. Elderly people without respiratory disease may have a FEV1/FVC within the LLN defined by a healthy reference population, yet have a FEV1/FVC $<70 \%$ pred. This scenario occurred more often in males than females in the present study because the mean age of males was 62 versus 56 yrs for females.

In conclusion, the current authors found that sex differences in symptom reporting, diagnoses and management of respiratory illness exist in primary-care practices. Physician awareness of this issue may help reduce this presumably unintentional bias. It may stem from a difference in the prevalence of breathlessness, a subjective indicator. Perhaps increased use of spirometry, an objective measure, would reduce the sexrelated biases and improve diagnosis and management of airway diseases in the primary-care practice setting.

\section{ACKNOWLEDGEMENTS}

The authors would like to thank the following physicians who participated in this study: A. Assemi; M. Buxton; G. Carvers; P. Coolican; M. Crabtree; C. Davis; R. Dawes; C. Deschenes; M. Dolan; W. Domanko; G. Houze; G. Jacques; H. Langill; J. Marston; G. Peters; H. Prins; E. Rivington; N. Soni; A. Thomas; and S. Wicklum. The authors would also like to thank J. Lowry for help with the study design and the study research assistants: G. Pratt, D. Bleskie and E. Gaudet.

\section{REFERENCES}

1 O'Donnell DE, Aaron SD, Bourbeau J, et al. Canadian Thoracic Society recommendations for management of chronic obstructive pulmonary disease- 2003. Can Respir J 2003; 10: Suppl A, 11A-33A.

2 Lemiere $C$, and the Canadian Adult Consensus Group of the Canadian Thoracic Society. Adult asthma consensus guidelines update 2003. Can Respir J 2004; 11: Suppl. A, 9a-18a.

3 Lethbridge-Cejku M, Schiller JS, Bernadel L. Summary health statistics for U.S. adults: National Health Interview Survey, 2002. Vital Health Stat 10 2004; 222: 1-151.

4 Varkey AB. Chronic obstructive pulmonary disease in women: exploring gender differences. Curr Opin in Pulm Med 2004; 10: 98-103.

5 de Torres JP, Casanova C, Hernandez C, Abreu J, AguirreJaime A, Celli BR. Gender and COPD in patients attending a pulmonary clinic. Chest 2005; 128: 2012-2016.

6 Ferris BG. Epidemiology standardization project. Am Rev Respir Dis 1978; 118: 1-88.

7 Knudson RJ, Lebowitz MD, Holberg CJ, Burrows B. Changes in the normal maximal expiratory flow-volume curve with growth and aging. Am Rev Respir Dis 1983; 127: 725-734.

8 Gomez FP, Rodriguez-Roisin R. Global Initiative for Chronic Obstructive Lung Disease (GOLD) guidelines for chronic obstructive pulmonary disease. Curr Opin Pulm Med 2002; 8: 81-86.

9 Hankinson JL, Odencrantz JR, Fedan KB. Spirometric reference values from a sample of the general U.S. population. Am J Respir Crit Care Med 1999; 159: 179-187.

10 CIBA Guest Symposium Report, Terminology, definitions and classification of chronic pulmonary emphysema and related conditions. Thorax 1959; 14: 286-289.

11 Chen Y, Dales R, Tang M, Krewski D. Obesity may increase the incidence of asthma in women but not in men: longitudinal observations from the Canadian National Population Health Surveys. Am J Epidemiol 2002; 155: 191-197.

12 Tashkin DP, Altose MD, Bleecker ER, et al. The lung health study: airway responsiveness to inhaled methacholine in smokers with mild to moderate airflow limitation. The Lung Health Study Research Group. Am Rev Respir Dis 1992; 145: 301-310.

13 Chapman KR, Tashkin DP, Pye DJ. Gender bias in the diagnosis of COPD. Chest 2001; 119: 1691-1695.

14 Franks P, Clancy CM, Naumburg EH. Sex, access, and excess. Ann Intern Med 1995; 123: 548-550.

15 Ayanian JZ, Epstein AM. Differences in the use of procedures between women and men hospitalized for coronary artery disease. N Eng J Med 1991; 325: 221-225. 